\title{
PENGARUH HIDROGEN TERHADAP KEKUATAN TARIK KELONGSONG BAHAN BAKAR NUKLIR BERBASIS PADUAN ZIRKONIUM
}

\author{
Rohmad Sigit, Fajar Al Afghani, Jan Setiawan, Sungkono \\ Pusat Teknologi Bahan Bakar Nuklir - BATAN, \\ Kawasan Puspiptek Serpong Gd.20 Tangerang Selatan, Banten 15314 \\ e-mail: sigitebp@batan.go.id \\ (Naskah diterima: 13-09-2017, Naskah direvisi: 15-10-2017, Naskah Disetujui: 27-10-2017)
}

\begin{abstract}
ABSTRAK
PENGARUH HIDROGEN TERHADAP KEKUATAN TARIK KELONGSONG BAHAN BAKAR NUKLIR BERBASIS PADUAN ZIRKONIUM. Selama operasi reaktor nuklir, zircaloy-4 (Zr-4) sebagai kelongsong bahan bakar nuklir berada pada lingkungan yang berpotensi menimbulkan kegagalan mekanik, terutama akibat interaksinya dengan hidrogen. Hidrogen berdifusi ke dalam kelongsong dan pada saat melewati batas kelarutan akan terpresipitasi menjadi hidrida rapuh yang menyebabkan degradasi sifat mekanik. Teknik pengujian tarik ring digunakan dalam penelitian ini untuk mengetahui pengaruh keberadaan hidrida terhadap kekuatan tarik kelongsong $\mathrm{Zr}$-4. Kelongsong $\mathrm{Zr}$-4 dipanaskan pada temperatur $500{ }^{\circ} \mathrm{C}$ dan $600{ }^{\circ} \mathrm{C}$ dalam kondisi vakum selama satu jam yang diikuti dengan proses hidrogenasi bertahap hingga mencapai tekanan 1000 mbar dan ditahan selama tiga jam sebelum didinginkan secara normal di dalam tungku. Dengan menggunakan persamaan gas ideal diperoleh kandungan hidrogen yang terserap oleh kelongsong Zr-4 berturut-turut sebesar 674 ppm dan 1215 ppm pada temperatur hidrogenasi 500 ${ }^{\circ} \mathrm{C}$ dan $600{ }^{\circ} \mathrm{C}$. Proses hidrogenasi pada temperatur $500{ }^{\circ} \mathrm{C}$ menyebabkan peningkatan kekerasan mikro hingga $36 \%$ dan pada temperatur $600{ }^{\circ} \mathrm{C}$ dapat meningkatkan kekerasan mikro hingga $49 \%$ jika dibandingkan dengan kelongsong $\mathrm{Zr}$-4 tanpa perlakuan. Sementara itu, analisis mikrotruktur menunjukkan presipitat hidrida lebih banyak menempati batas butir. Presipitat hidrida lebih panjang dan tebal pada temperatur hidrogenasi yang lebih tinggi. Kenaikan jumlah hidrogen menghasilkan kenaikan nilai tegangan sebesar 4,4\%, penurunan nilai regangan sebesar 2,1\% dan kenaikan level kekerasan mikro Vickers sebesar $13 \%$. Hal ini menunjukkan bahwa keberadaan presipitat hidrida dalam kelongsong meningkatkan kekuatan tarik dan menurunkan daktilitasnya..
\end{abstract}

Kata kunci: Hidrogen, kekuatan tarik, kelongsong, uji tarik ring, daktilitas. 


\section{ABSTRACT}

HYDROGEN IMPACTS ON THE TENSILE STRENGTH OF ZIRCONIUM ALLOY BASED FUEL CLADDING. During reactor operation, zircaloy-4 (Zr-4) as fuel cladding is under an environment that can potentially cause mechanical failure, especially by the effect of cladding-hydrogen interaction. Hydrogen would diffuse and precipitate to form brittle hydrides when the solubility limit is surpassed. In this experiment, ring tensile test method was used to examine the effect of hydrides existence on tensile strength of Zr-4 cladding. The Zr-4 sample was annealed at $500{ }^{\circ} \mathrm{C}$ and $600^{\circ} \mathrm{C}$ for an hour in vacuum condition and followed by hydriding with a pressure up to 1000 mbar with 3 hours holding time and slow cooling. According to ideal gas equation, hydrogen content in Zr-4 reaches about $674 \mathrm{ppm}$ and $1215 \mathrm{ppm}$ at hydriding temperature of $500{ }^{\circ} \mathrm{C}$ and $600{ }^{\circ} \mathrm{C}$ respectively. Microstructure observation shows that hydrides precipitate was formed at grain boundaries. The hydrides were found to be longer and thicker at higher hydriding temperature. As the hydrogen content increases, the ring tensile test shows increasing stress at $4,4 \%$, decreasing strain at 2,1\% and increasing microhardness level at $13 \%$. This result confirms that the existence of hydrides precipitates in cladding has an effect of increasing the tensile strength and decreasing the ductility obviously.

Keywords: Hydrogen, tensile strength, cladding, ring tensile test, ductility. 


\section{PENDAHULUAN}

Zircaloy-4 (Zr-4) merupakan salah satu paduan material yang umum digunakan sebagai bahan struktur untuk reaktor nuklir, terutama sebagai kelongsong bahan bakar. Zr-4 sebagai kelongsong bahan bakar berada pada lingkungan yang di dalamnya terdapat kombinasi antara proses iradiasi, oksidasi dan serapan hidrogen yang berpotensi menyebabkan degradasi sifat mekanik. Pada kondisi operasi normal, hal tersebut sudah diperhitungkan dalam desain keselamatan sebuah reaktor nuklir, tetapi pada kondisi transien, kehilangan aliran pendingin primer atau Loss of Cooling Accident (LOCA) misalnya, kombinasi faktor tersebut dapat menyebabkan situasi fatal bagi keselamatan reaktor nuklir. Degradasi sifat mekanik yang diikuti dengan kerusakan kelongsong bahan bakar nuklir sebagian besar disebabkan oleh temperatur tinggi yang disertai oleh serapan hidrogen seperti pada skenario terjadinya LOCA[1]. Oleh karena itu, pengaruh hidrogen terhadap degradasi sifat mekanik kelongsong $\mathrm{Zr}-4$ menjadi salah satu perhatian utama dalam pengoperasian reaktor nuklir, terutama setelah peristiwa kebocoran reaktor nuklir di Fukushima-Daichi [2].

Terkait aspek dasar keselamatan dan integritas mekanik, kelongsong bahan bakar nuklir merupakan salah satu lapisan pertahanan awal. Oleh karena itu, karakter Zr-4 sebagai kelongsong bahan bakar sangat penting diketahui untuk memprediksi pembentukan presipitat hidrida dan mengetahui berbagai macam dampak yang disebabkan adanya presipitat hidrida tersebut. Pengaruh paling besar dari serapan hidrogen pada kelongsong Zr-4 adalah terkait karakter daktilitasnya[3]. Kelongsong Zr-4 dengan kandungan hidrogen sebesar $225 \mathrm{ppm}$ memiliki daktilitas yang lebih rendah dibandingkan dengaan yang hanya 60 ppm[4]. Penelitian lain menyebutkan bahwa pada saat kandungan hidrogen mencapai 600 ppm, kelongsong $\mathrm{Zr}-4$ mulai kehilangan daktilitasnya bahkan pada kondisi yang ekstrim dengan kandungan hidrogen sekitar $\sim 5000$ ppm, kelongsong Zr-4 hanya memiliki regangan sebesar $1 \%[5,6]$. Salah satu teknik pengujian daktilitas adalah pengujian tarik transversal/ring yang telah banyak dilakukan oleh para peneliti[7-10]. Pengujian tarik ring memiliki beberapa kelebihan, terutama untuk pengujian material pasca iradiasi. Hal ini terkait dengan kemudahan dalam preparasi sampel dan kemudahan dalam menempatkan peralatan uji tarik di dalam hot cel[11].

Penelitian ini bertujuan untuk mengetahui karakter hidrida dan degradasi kekuatan mekanik akibat keberadaan hidrogen dalam kelongsong $\mathrm{Zr}-4$. Uji mekanik yang dilakukan adalah pengujian tarik ring dan kekerasan mikro kelongsong $\mathrm{Zr}-4$ pada simulasi kondisi transien dengan melakukan hidrogenasi pada temperatur 500 ${ }^{\circ} \mathrm{C}$ dan $600{ }^{\circ} \mathrm{C}$. Pemilihan temperatur hidrogenasi berdasarkan kondisi diatas dan dibawah temperatur eutektik diagram fasa $\mathrm{Zr}$-H untuk mewakili karakter matriks $\mathrm{Zr}$ pada dua fasa yang berbeda. Selain itu, temperatur kerja hidrogenasi merupakan temperatur awal terjadinya LOCA yang umumnya berkisar antara $600-900{ }^{\circ} \mathrm{C}[6]$.

\section{METODOLOGI}

Penelitian ini menggunakan kelongsong $\mathrm{Zr}$-4 non iradiasi yang biasa digunakan di reaktor tipe PWR (Power Water Reactor) dengan komposisi kimia dalam persen berat $\mathrm{Zr} 98,27 \%$, Sn 1,4\%, Fe $0,21 \%$ dan $\mathrm{Cr}$ 0,12\%[12]. Kelongsong $\mathrm{Zr}-4$ mempunyai diameter luar $13,25 \mathrm{~mm}$, ketebalan 0,45 $\mathrm{mm}$ dan panjang $50 \mathrm{~mm}$.

Sampel uji $\mathrm{Zr}-4$ dipanaskan pada temperatur $500{ }^{\circ} \mathrm{C}$ dan $600{ }^{\circ} \mathrm{C}$ dalam kondisi vakum orde $10^{-2}$ mbar selama 1 jam untuk optimalisasi homogenitas temperatur sampel. Gas hidrogen dimasukkan secara bertahap hingga mencapai tekanan 1000 mbar dan dibiarkan selama 3 jam. Setelah proses serapan hidrogen dilakukan, sistem 
didinginkan secara perlahan hingga mencapai temperatur ruang. Jumlah hidrogen yang diserap sampel dikendalikan berdasarkan nilai beda tekanan dan dihitung dengan menggunakan persamaan gas ideal $\triangle P V=\Delta n R T$, dengan $\Delta n$ adalah jumlah hidrogen yang diserap dan $\Delta P$ adalah beda nilai tekanan selama proses pengisian gas hidrogen.

Pengamatan mikrostruktur dilakukan dengan menggunakan mikroskop optik Leitz pada perbesaran 200. Untuk mengetahui pengaruh hidrida pada degradasi sifat mekanik sampell uji dilakukan pengujian tarik spesimen ring dan uji kekerasan mikro. Spesimen uji tarik ring didapatkan dengan memotong kelongsong yang telah dihidriding dengan lebar $3 \mathrm{~mm}$ satu lingkaran penuh. Desain perlengkapan uji tarik ini berupa mandrel setengah lingkaran dari diameter material uji seperti yang terlihat pada Gambar 1. Perlengkapan uji tarik ring dapat berupa dua mandrel setengah lingkaran yang dipasangkan pada grip seperti dalam ASTM D2290[9,13] atau dua pin setengah lingkaran yang terpasang pada grip. Pengujian tarik ring menggunakan mesin uji tarik Shimadzu AGS-X dengan beban $10 \mathrm{kN}$ dan laju penarikan sebesar $1 \mathrm{~mm} / \mathrm{s}$ pada temperatur kamar. Uji kekerasan dilakukan dengan menggunakan alat uji kekerasan mikro LECO LM800 AT dengan parameter beban sebesar $200 \mathrm{gf}$ dan waktu penjejakan selama 10 detik.

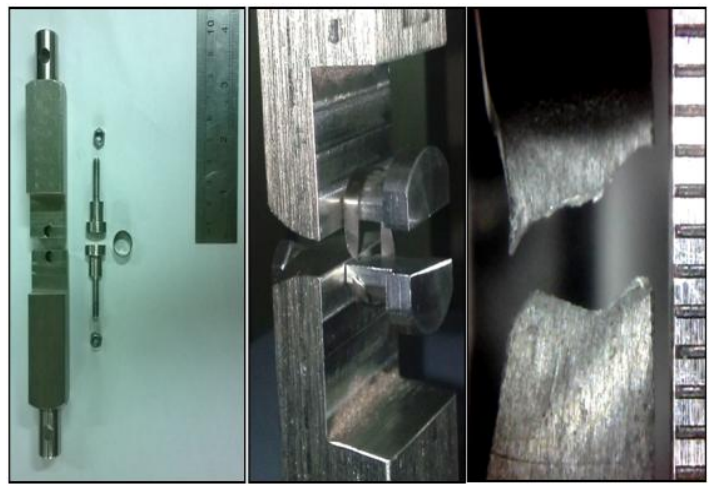

Gambar 1. Perlengkapan uji tarik ring.

\section{HASIL DAN PEMBAHASAN}

\section{a) Mikrostruktur}

Mikrostruktur untuk sampel uji Zr-4 tanpa perlakuan dan yang telah dikenakan hidrogenasi ditampilkan pada Gambar 2, 3 dan 4. Pada Gambar 2 dengan jelas terlihat adanya mikrostruktur umum $\alpha-Z r$ tanpa keberadaan fasa lainnya.

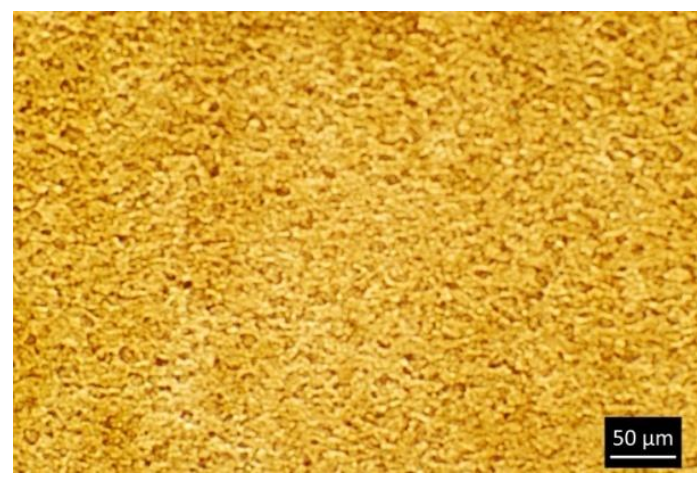

Gambar 2. Mikrostrukur $\quad \mathrm{Zr}-4 \quad$ tanpa perlakuan pada perbesaran $200 x$

Kondisi berbeda terjadi pada sampel uji yang telah dihidrogenasi pada temperatur $500{ }^{\circ} \mathrm{C}$ dan $600{ }^{\circ} \mathrm{C}$. Menggunakan pendekatan persamaan gas ideal, diperoleh serapan hidrogen pada dua temperatur kerja hidrogenasi berturut-turut adalah sebesar 674 ppm dan 1215 ppm. Selain karena temperatur hidrogenasi yang tinggi, tingginya kandungan $\mathrm{Sn}$ dalam bahan $\mathrm{Zr}$-4 yang digunakan dalam penelitian ini menyebabkan pecahnya lapisan oksida akan lebih cepat terjadi sehingga memberi peluang hidrogen untuk lebih mudah terserap ke dalam $\mathrm{Zr}$-4[14].

Keberadaan hidrogen dalam sampel Zr-4 dapat berada dalam bentuk larutan padat maupun presipitat hidrida yang terbentuk saat batas kelarutan tercapai[15]. Laju pendinginan rendah yang digunakan menyebabkan pembentukan fasa $\delta$-hidrida dalam matriks $\alpha-\operatorname{Zr}[16]$. Fasa hidrida dalam bentuk platelet dengan panjang $\sim 40 \mu \mathrm{m}$ mulai teramati cukup banyak pada sampel uji yang dihidrogenasi pada temperatur 
sekitar $500{ }^{\circ} \mathrm{C}$ seperti yang ditunjukkan pada Gambar 3.

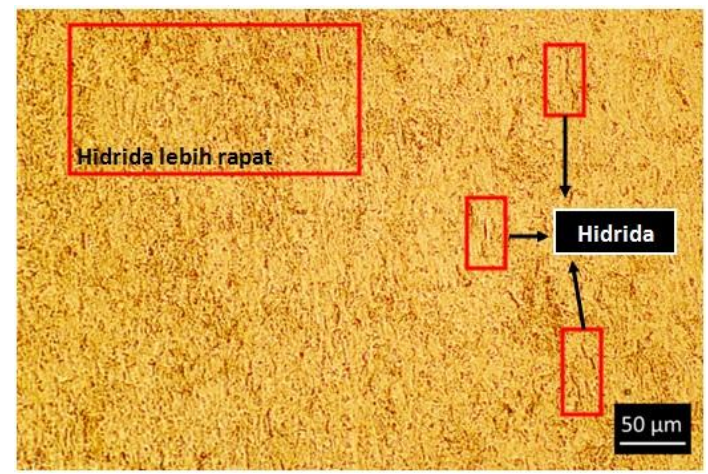

Gambar 3. Fasa Hidrida $\mathrm{Zr}-4$ yang dihidrogenasi pada temperatur $500{ }^{\circ} \mathrm{C}$.

Pada saat hidrogen terserap oleh Zr-4 kecenderungan awal dari hidrida adalah mengisi batas butir. Hal ini terkait dengan tingkat energi yang dipengaruhi oleh temperatur hidrogenasi. Pada kondisi fasa $\beta-Z r$ yang dicapai pada temperatur sekitar $550{ }^{\circ} \mathrm{C}$, hidrogen lebih mudah terserap jika dibandingkan saat zircaloy berada pada fasa $\alpha-Z r$. Selain itu, waktu interaksi yang cukup singkat dan tekanan gas yang relatif kecil juga berkontribusi terhadap jumlah hidrogen yang terserap ke dalam kelongsong $\mathrm{Zr}-4$. Difusi hidrogen ke dalam butir berpotensi terjadi pada temperatur dan tekanan hidrogenasi yang lebih tinggi serta waktu interaksi yang lebih lama.

Keberadaan presipitat hidrida di batas butir dengan sifatnya yang keras dan rapuh didalam matriks yang ulet, alur perpatahan dapat merambat dengan mudah melalui material sepanjang batas butir. Hal ini tergambar jelas pada material uji yang dihidrogenasi pada temperatur $600{ }^{\circ} \mathrm{C}$. Dengan jumlah hidrida yang lebih banyak pada temperatur hidrogenasi yang lebih tinggi. Presipitat hidrida yang terbentuk akan cenderung mengisi ruang yang dibuat hidrida sebelumnya. Proses tersebut akan berulang seiring bertambahnya hidrogen yang diserap ke dalam $\mathrm{Zr}-4$ dan akan menyebabkan retak pada batas butir saat ukuran hidrida mencapai titik kritis. Retak pada satu batas butir akan menginisisasi terjadinya perpatahan pada material dalam skala yang lebih luas seperti yang ditunjukkan pada Gambar 4.

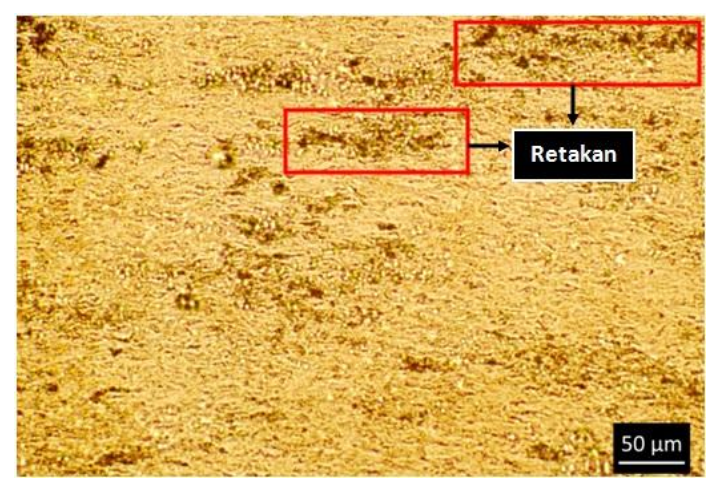

Gambar 4. Retakan yang mulai muncul pada hidrogenasi temperatur $600^{\circ} \mathrm{C}$.

Hasil ini sejalan dengan penelitian Kim dan Wang[18,19] yang menyebutkan bahwa diatas $600 \mathrm{ppm}$ hidrida akan kehilangan daya kohesi terhadap matriks fasa $\alpha$-Zr. Hasil penelitian ini menegaskan bahwa keberadaan hidrida menyebabkan sifat rapuh yang ekstrim sehingga sampel uji menjadi patah bahkan hanya dengan pembebanan yang sangat rendah.

\section{b) Uji Mekanik}

Hasil pengujian tarik ring untuk sampel standar $\mathrm{Zr}-4$ dan sampel $\mathrm{Zr}$-4 yang telah dihidrogenasi ditunjukkan pada Tabel.2 dan Gambar 5. Data hasil pengujian menunjukkan bahwa nilai regangan sampel uji menurun sebesar 2,1\% dan tegangan yang meningkat sebesar $4,4 \%$ seiring dengan kenaikan jumlah hidrogen dalam sampel. Peneliti Kim mengonfirmasi dalam penelitiannya bahwa pada jumlah hidrogen sebesar 600 dan 1000 ppm dalam zircaloy menurunkan nilai regangan sebesar 2,8 \% dan menaikkan tegangan sebesar $5,1 \%[17]$. 
Tabel 1. Data hasil pengujian tarik ring material uji Zr-4 untuk berbagai kondisi.

\begin{tabular}{|l|c|c|c|}
\hline \multicolumn{1}{|c|}{ Kondisi } & $\begin{array}{c}\text { Tegangan } \\
\text { maksimum (MPa) }\end{array}$ & $\begin{array}{c}\text { Regangan maksimum } \\
(\%)\end{array}$ & $\begin{array}{c}\text { Break stress } \\
(\mathrm{MPa})\end{array}$ \\
\hline Standar & 478,8 & 18,9 & 456,2 \\
\hline Hidrogenasi $500^{\circ} \mathrm{C}$ & 416,0 & 17,3 & 307,9 \\
\hline Hidrogenasi $600^{\circ} \mathrm{C}$ & 434,1 & 16,7 & 314,6 \\
\hline
\end{tabular}

Kenaikan nilai tegangan pada $\mathrm{Zr}$-4 dengan jumlah hidrogen yang lebih tinggi mengindikasikan terjadinya peningkatan kekuatan. Hal ini disebabkan oleh sifat hidrogen yang terlarut dalam matriks $\mathrm{Zr}$ tetapi masih dibawah nilai batas kelarutan. Selain itu, peningkatan tegangan maksimum disebabkan oleh sifat kaku yang dimiliki oleh hidrida itu sendiri jika dibandingkan dengan matriks $\alpha$-Zr. Kondisi diatas memungkinkan terjadi bila hidrida belum mencapai ukuran kritis untuk mencapai titik retak.

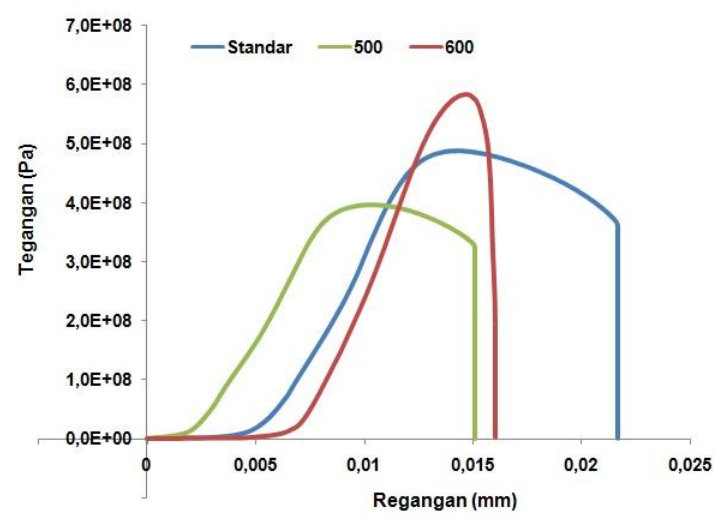

Gambar 5. Grafik tegangan terhadap regangan $\mathrm{Zr}-4$ standar dan yang telah dihidrogenasi.

Di sisi lain, peningkatan jumlah hidrogen yang terserap dalam sampel yang berakibat turunnya nilai regangan, terkait erat dengan penurunan daktilitas bahan. Selain karena friksi internal dislokasi karena larutnya hidrogen dalam matriks $\alpha-Z r[19]$, penurunan nilai regangan juga disebabkan oleh ukuran dan arah pembentukan presipitat hidrida[20]. Presipitat hidrida yang lebih panjang akan memiliki nilai regangan yang lebih rendah jika dibandingkan dengan hidrida yang lebih pendek. Hal ini dikonfirmasi dengan presipitat hidrida yang terbentuk pada sampel uji yang dihidrogenasi pada temperatur $600{ }^{\circ} \mathrm{C}$ memiliki panjang hampir 1,5 kali dari presipitat hidrida yang dihidrogenasi pada temperatur $500{ }^{\circ} \mathrm{C}$.

Uji kekerasan mikro pada sampel uji kelongsong Zr-4 menunjukkkan bahwa tidak ada perubahan signifikan nilai kekerasan mikro Vickers pada sampel uji yang dipanaskan tanpa gas hidrogen terhadap sampel uji semula. Kenaikan nilai kekerasan mikro hanya berkisar $1,1 \%$ yang disebabkan oleh terbentuknya lapisan oksida pada permukaan material.

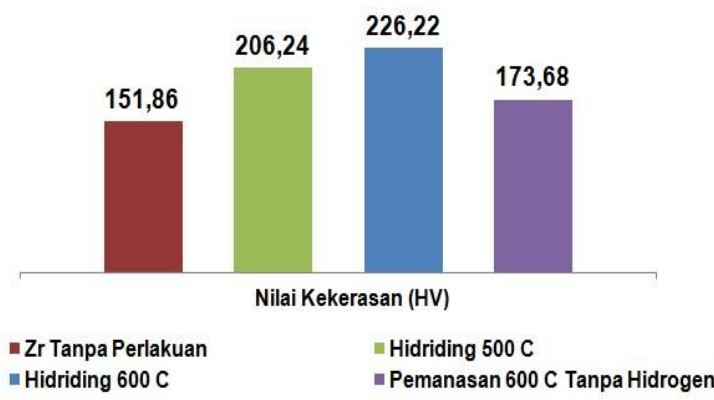

Gambar 6. Kekerasan mikro Zr-4 tanpa perlakuan dan dengan perlakuan.

Kondisi berbeda terjadi pada kelongsong Zr-4 yang dikenakan hidrogenasi pada temperatur $500{ }^{\circ} \mathrm{C}$ dan $600{ }^{\circ} \mathrm{C}$. Pada temperatur $500{ }^{\circ} \mathrm{C}$ diperoleh kekerasan mikro meningkat secara signifikan hingga mencapai nilai $36 \%$ jika dibandingkan dengan kelongsong $\mathrm{Zr}$-4 tanpa perlakuan. Sementara itu, kekerasan mikro sampel kelongsong $\mathrm{Zr}$-4 yang dikenakan hidrogenasi pada temperatur $600{ }^{\circ} \mathrm{C}$ meningkat sebesar $49 \%$ jika dibandingkan dengan kelongsong $\mathrm{Zr}-4$ tanpa perlakuan. Terbentuknya presipitasi hidrida sangat 
memegang peranan penting terhadap kenaikan nilai kekerasan mikro. Nilai kekerasan presipitat hidrida bahkan bisa mencapai $70 \%$ dari nilai kekerasan matriks $\alpha-\operatorname{Zr}[6]$. Selain itu, keberadaan hidrogen dalam bentuk larutan padat interstisi dalam matriks $\alpha-Z r$ juga berkontribusi terhadap kenaikan nilai kekerasan. Hal ini ditunjukkan oleh kecenderungan homogenitas nilai kekerasan pada titik indentasi yang bervariasi sepanjang sampel uji Zr-4.

\section{SIMPULAN}

Pada parameter tekanan, periode hidrogenasi dan laju pendinginan yang sama, sampel uji Zr-4 menyerap hidrogen lebih banyak pada temperatur hidrogenasi yang lebih tinggi. Presipitat hidrida yang terbentuk relatif lebih panjang dan tebal. Presipitat hidrida cenderung berkumpul pada batas butir dan di beberapa tempat mulai menginisiasi terjadinya retakan. Pengujian mekanik meliputi uji tarik ring dan kekerasan mikro material uji Zr-4 pasca hidrogenasi pada temperatur $500{ }^{\circ} \mathrm{C}$ dan $600{ }^{\circ} \mathrm{C}$ menghasilkan kenaikan nilai kekuatan tarik dan penurunan daktilitas.

\section{UCAPAN TERIMA KASIH}

Ucapan terima kasih penulis
sampaikan pada Pusat Teknologi Bahan
Bakar Nuklir yang telah memfasilitasi
penelitian ini dengan anggaran DIPA 2016.
Penulis juga mengucapkan terima kasih pada
Bapak Dr. Hadi Suwarno, M.Eng, saudara
Yatno Dwi Agus Susanto, A.Md, Suyoto,
S.ST dan Guswardani yang telah banyak
membantu selama proses pengambilan data
dan pengujian.

\section{DAFTAR PUSTAKA}

[1] J. Desquines, D. Drouan, M. Billone, M. P. Puls, P. March, S. Fourgeaud, et.al "Influence of temperature and hydrogen content on stress-induced radial hydride precipitation in Zircaloy4 cladding," Journal of Nuclear Materials, vol. 453, no. 1-3, pp. 131-
150, 2014.

[2] H. H. Hsu and L. W. Tsay, "Fracture properties of hydrided Zircaloy-4 cladding in recrystallization and stress-relief anneal conditions," Journal of Nuclear Materials, vol. 422, no. 1-3, pp. 116-123, 2012.

[3] S. Kim, J. Bang, D. Kim, I. Lim, Y. Yang, K. Song, and D. Kim, "Hoop strength and ductility evaluation of irradiated fuel cladding," Nuclear Engineering and Design, vol. 239, pp. 254-260, 2009.

[4] A. Zielinski and S. Sobieszczyk, "Hydrogen-enhanced degradation and oxide effects in zirconium alloys for nuclear applications," Journal of Hydrogen Energy.vol. 36, 2011.

[5] J. Bair, M. Asle, and M. Tonks, "A review on hydride precipitation in zirconium alloys," Journal of Nuclear Materials, vol. 466, pp. 12-20, 2015.

[6] A. Pshenichnikov, J. Stuckert, and M. Walter, "Microstructure and mechanical properties of Zircaloy-4 cladding hydrogenated at temperatures typical for loss-ofcoolant accident (LOCA) conditions," Nuclear Engineering and Design, vol. 283, pp. 33-39, 2015.

[7] H. Cha, J. Won, K. Jang, J. An, and K. Kim, "Tensile hoop stress-, hydrogen content- and cooling rate-dependent hydride reorientation behaviors of $\mathrm{Zr}$ alloy cladding tubes," Journal of Nuclear Materials, vol. 464, pp. 5360, 2015.

[8] H. Kim, J. H. Yang, W. Kim, and Y. Koo, "Development status of accidenttolerant fuel for light water reactors in Korea," Nuclear Engineering and Technology., no. August 2016, 2015.

[9] C. P. Dick and Y. P. Korkolis, "Mechanics and full-field deformation study of the ring hoop tension test," International Journal of Solids and Structures, vol. 51, no. 18, pp. 30423057, 2014. 
[10] Y. Meng, Y. Qiwei, and W. Pengfei, "ISCC behavior evaluation of N36 zirconium alloy cladding using ring tensile test," Rare Metal Materials Engineering, vol. 44, no. 1, pp. 58-61, 2015.

[11] F. Nagase, T. Sugiyama, and T. Fuketa, "Optimized ring tensile test method and hydrogen effect on mechanical properties of zircaloy cladding in hoop direction," Journal of Nuclear Science and Technology, vol. 46, no. No.6, pp. 545-552, 2009.

[12] R. Sigit, H. Suwarno, and B. Soegijono, "Characterization of zircaloy-4 after gaseous hydriding at the temperature range of $350-600{ }^{\circ} \mathrm{C}$," Atom Indonesia Journal, vol. 42, no. 3, pp. 137-143, 2016.

[13] M.K. Samal, "Estimation of transverse tensile behavior of zircaloy pressure tubes using ring-tensile test and finite element analysis," Proceeding of the Institution of Mechanical Engineers, Part C: Journal of Mechanical Engineering Science, vol. 227, pp. 1177-1186, 2013.

[14] H. Hsu, M. Chiang, and Y. Chen, "The influence of hydride on fracture toughness of recrystallized Zircaloy-4 cladding," Journal of Nuclear Materials, vol. 447, no. 1-3, pp. 5662, 2014.

[15] J. Bair, M. Asle Zaeem, and M. Tonks,
"A review on hydride precipitation in zirconium alloys," Journal of Nuclear Materials, vol. 466, pp. 12-20, 2015.

[16] S. Suman, M. K. Khan, M. Pathak, R. N. Singh, and J. K. Chakravartty, "Hydrogen in zircaloy: Mechanism and its impacts, Journal of Hydrogen Energy, vol. 40, no. 17, pp. 59765994, 2015.

[17] J. H. Kim, M. H. Lee, B. K. Choi, and $Y$. H. Jeong, "Effects of oxide and hydrogen on the circumferential mechanical properties of Zircaloy-4 cladding," Nuclear Engineering and Design, vol. 236, pp. 1867-1873, 2006.

[18] Z. Wang, U. Garbe, H. Li, R. P. Harrison, K. Toppler, A. J. Studer, et al, "Hydride precipitation and its influence on mechanical properties of notched and unnotched Zircaloy-4 plates," Journal of Nuclear Materials, vol. 436, no. 1-3, pp. 84-92, 2013.

[19] P. Chakraborty, A. Moitra, and T. Sahadasgupta, "Effect of hydrogen on degradation mechanism of zirconium : A molecular dynamics study," Journal of Nuclear Materials, vol. 466, pp. 172-178, 2015.

[20] J. Kim, T. Kim, D. Kook, and Y. Kim, "Effects of hydride morphology on the embrittlement of Zircaloy-4 cladding," Journal of Nuclear Materials, vol. 456, pp. 235-245, 2015. 